\title{
Cerebral Aspergilloma in Patient with Diabetes - A Case Report with Short Literature Review
}

\author{
Koni Ivanova ${ }^{1 *}$, Stefan Valkanov ${ }^{2}$, Bozhidar Petrov $^{2}$, Ivan Mindov², Maya Gulubova ${ }^{1}$ \\ ${ }^{1}$ Department of General and Clinical Pathology, Trakia University, Faculty of Medicine, Stara Zagora, Bulgaria; ${ }^{2}$ Department of \\ Neurosurgery, Trakia University, Faculty of Medicine, Stara Zagora, Bulgaria
}

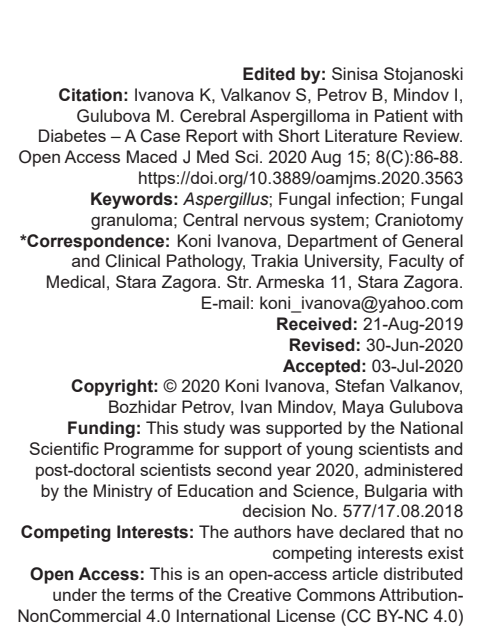

Abstract

BACKGROUND: In the recent years, the incidence of fungal brain abscess has been rising as a result of the increased use of corticosteroid therapy, broad-spectrum antimicrobial therapy, and immunosuppressive agents. Aspergillosis of the central nervous system (CNS) is reported in $10 \%-20 \%$ of the patients having invasive fungal disease. Commonly, the disease is observed in immunocompromised or immunosuppressed patients; also, patients who suffered traumatic head injury are reported as well to develop the infection due to due cranial defect accompanied by dural tearing. Symptoms are non-specific neurologic manifestations.

CASE PRESENTATION: We presented a case of a 68-year-old man who had diabetes mellitus type II. He was admitted to in neurosurgery clinic due reported head trauma. Initially, he complained of a headache, dizziness slurred speech, nausea, and pain in the right ear with tinnitus and pain in his right upper teeth - continuous for a month. The patient was conscious, adequate, Glasgow Coma Scale - 15 points, with left-sided hemiparesis general symptomatic syndrome. An emergent computed tomography scan was performed, which showed tumorous formation in patient's right temporal lobe that had mass effect and compression of the right lateral ventricle. The patient was discussed on a emergent clinical counsel and it was decided that he was shown for surgical treatment An informed consent was signed by the patient and his relatives. After the surgery intervention - the histological result of the biopsy was aspergilloma of the brain and the microbiological result was Aspergillus fumigatus.

CONCLUSION: The prognosis for CNS aspergillosis is poor, but the early diagnosis and effective medical and surgical treatments may reduce morbidity and mortality.

\section{Introduction}

Aspergillosis of the central nervous system (CNS) is reported in $10 \%-20 \%$ of the patients having invasive fungal disease. Commonly, the disease is observed in immunocompromised or immunosuppressed patients, also patients who suffered traumatic head injury are reported as well to develop the infection due to the cranial defect accompanied by dural tearing [1], [2]. Aspergillosis of brain is rare condition and commonly seen in immunocompromised or immunosuppressed patients, such as patients with hematopoietic stem cell transplant, AIDS, patients on immunosuppressive drugs, uncontrolled diabetes mellitus, and some patients with cancer [3], [4]. There are various pathologic presentation forms of this infection: Aseptic and persistent meningitis, mycotic aneurysm, ischemic and hemorrhagic infarcts, and the tumor-like form or aspergilloma [5], [6]. Aspergillus infection could reach the brain directly from the nasal sinuses through vascular channels (contiguous source $25 \%-50 \%$ of the cases), also from the lungs (most commonly) and gastrointestinal system by blood borne (hematogenous dissemination 20\%-35\%). Trauma could lead to brain abscess formation as a result of an open cranial fracture with dural breach or foreign body injury or as a sequela of neurosurgery - and the reported incidence is $2.5 \%-10 \%$. [7], [8], [9]. Aspergillosis of the CNS is an infrequent medical condition and does not have a specific imaging pattern and hence poses a difficult diagnostic challenge, carry higher risks of morbidities and mortality as compared to other infective processes [10]. The most common presenting symptoms are non-specific neurologic manifestations - general brain symptomatic and/or also focal neurologic symptoms, depending on the localization of the process [11]. In this article, we present a case of patient with cerebral aspergilloma.

\section{Case Report}

A 68-year-old man was brought to the emergency department. He complained of a headache, complained of dizziness, slurred speech, nausea, tinnitus, and pain in the right ear and also right upper teeth continuing a month. There was no history of fever. He has diabetes type II, adenoma of the prostate gland and has amputation of the left arm. Hematological and 
biochemical blood investigation were normal except for glucose $14.9 \mathrm{mmol} / \mathrm{l}$ and CRP $24.7 \mathrm{mg} / \mathrm{l}$.

\section{Imaging}

Chest X-ray was without any pathological changes. The computed tomography (CT) scan revealed - the ventricular system was partially compressed in the area of the right lateral ventricle without evident brain shifting. The basal cisterns were normal. There was tumor formation in right temporal lobe, three formations with ring form - hypodense mass 92/92 mm, 12.3/14.6 $\mathrm{mm}$ and $47 / 77 \mathrm{~mm}$ and evident perifocal edema.

\section{Neurosurgical intervention}

The right-sided temporoparietal osteoplastic craniotomy was planned. Intraoperative a biopsy sample was taken from the pathological process. The reported data of the biopsy were for inflammation processes, which lead to change in the initially planned intervention - with microsurgical gross total resection of the pathological

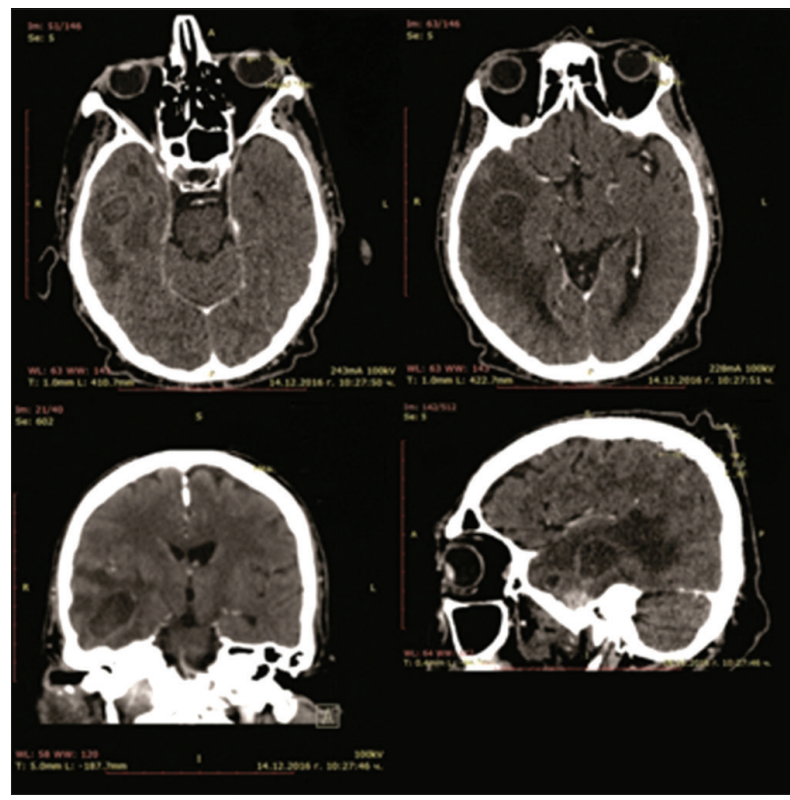

Figure 1: Polycystic formation with significant peripheral edema

process followed by bony dural decompression. The pathogen was confirmed through Grocott staining (Figures 1-3). The microbiological result was Aspergillus fumigatus. On the final histologic result - abscessus with massive neutrophilic infiltration and the cytology result was hemorrhagic exudate with autolytic changes.

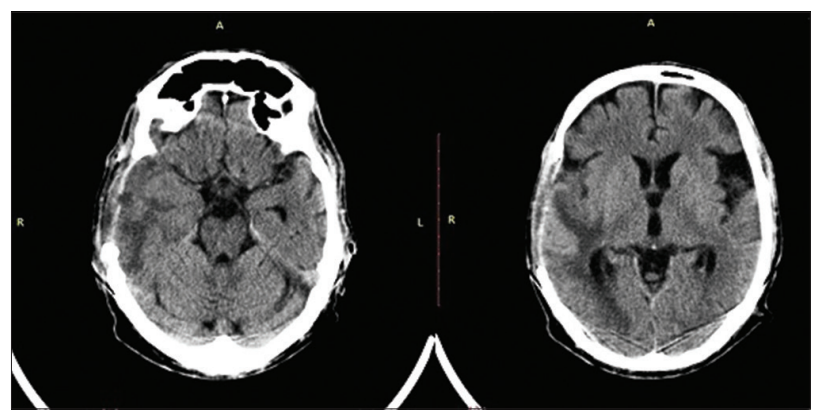

Figure 2: Postoperative gliotic brain changes - after two months

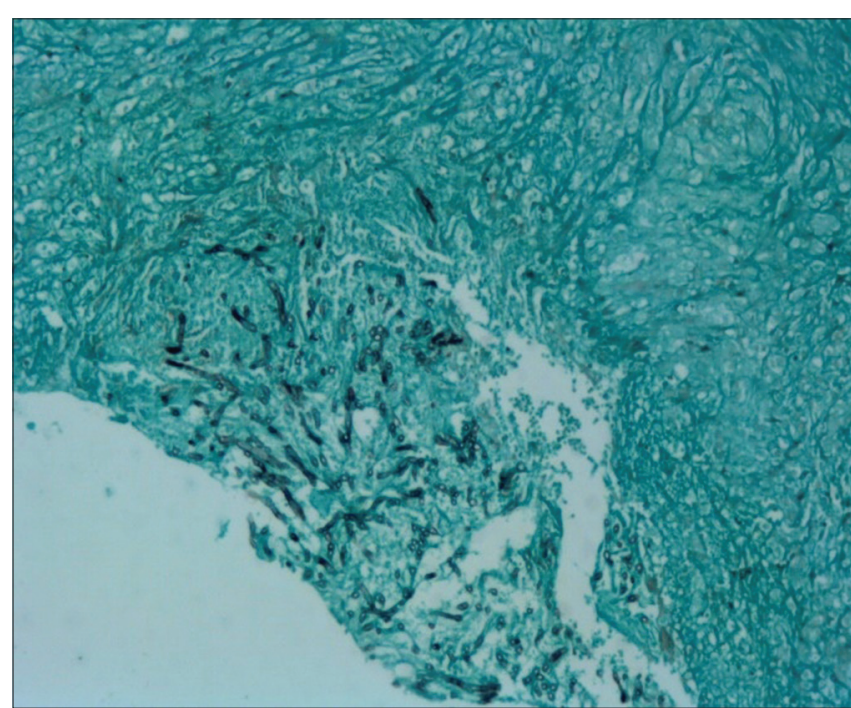

Figure 3: Histopathologic features of (pigmented in black) fungal hyphae in specimen of aspergillus granuloma -Grohott Staining x 200

\section{Discussion}

Intracranial granuloma is the most often presentation of the Aspergillus infection. Based on CT findings in the similar masses, the differential diagnosis for the lesion includes:

Locally invasive skull base neoplasm squamous cell carcinoma (SCCa); soft-tissue mass in the nasopharynx; fungal infection often angioinvasive with internal carotid artery occlusion (rare in SCCa)

Multiple ring-enhancing brain lesions - (1) patientswithmetastases, pyogenicabscesses, parasites, and septic emboli and (2) immunocompromised patients - tuberculosis, toxoplasmosis, and primary CNS lymphoma. Tuberculoma, abscess, meningioma, or glioma depending on location of the lesion [12].

The rout of infection from Aspergillus has been described as per contiguous source (direct extension), through hematogenous dissemination or as primary intracranial lesion [5], [13], [14]. In the study of 40 patients with intracranial aspergilloma, Dubey et al. [6] described that the most common location of Aspergillus were the frontal lobes in $25 \%$ and anterior cranial fossa without frontal lobe involvement.

In a study of Murthy et al. [14], they were investigated 21 patients with brain aspergillosis infection in South India, one of the patients was with similar clinic to our case, with a brain infection through the ear. Some authors [4], [7] in different study of a larger group of patients reported that the presence of aspergilloma is associated with significant morbidity and mortality. In a series of 13 cases of aspergillosis, three patients were treated successfully and recovered, but three died after surgery and antibiotic treatment [10]. Sharma et al. [13] reported overall mortality of $50 \%$. 


\section{Conclusion}

The prognosis for CNS aspergillosis is very poor, with most reported cases being fatal. In conclusion, we may state that early diagnosis in combination with effective medical and surgical treatments is essential to preserve neurologic function and assure a good quality of life and may reduce morbidity and mortality.

\section{References}

1. McCarthy M, Walsh TJ. Space-occupying fungal lesions. In: Scheld WM, Whitley RJ, Marra CM, editors. Infections of the Central Nervous System. $4^{\text {th }}$ ed. Philadelphia, PA: Lippincott Williams \& Wilkins; 2014. p. 711-28.

2. Ruhnke M, Kofla G, Otto K, Schwartz S. CNS aspergillosis: Recognition, diagnosis and management. CNS Drugs. 2007;21:659-76. 2007https://doi. org/10.2165/00023210-200721080-00004 PMid: 17630818

3. Figueiredo EG, Fonoff E, Gomes M, Macedo E, Marino R Jr. Tumoral form of aspergillosis in central nervous system (cerebral aspergilloma): Case report. Sao Paulo Med J. 2003;121(6):2513. https://doi.org/10.1590/s1516-31802003000600007 PMid:14989142

4. Golin V, Sprovieri SR, Cançado JE, Daniel JW, Mimica LM. Aspergillosis of the central nervous system. Sao Paulo Med J. 1996;114(5):1274-7. https://doi.org/10.1590/ s1516-31801996000500007 PMid:9239928

5. Nadkarni T, Goel A. Aspergilloma of the brain: An overview. J Postgrad Med. 2005;51 Suppl 1:S37-41.

PMid:16519254
6. Dubey A, Patwardhan RV, Sampth S, Santosh V, Kolluri S, Nanda A. Intracranial fungal granuloma: Analysis of 40 patients and review of the literature. Surg Neurol. 2005;63(3):254-60. https://doi.org/10.1016/j.surneu.2004.04.020

PMid: 15734518

7. Chowdhury FH, Haque MR, Khan SK, Alam SM. Cerebral aspergilloma in a SLE patient: A case report with short literature review. Asian J Neurosurg. 2014;9(2):58-61. https://doi. org/10.4103/1793-5482.136710

PMid:25126119

8. Klein M, Pfister HW, Tunkel AR, Scheld WM. Brain abscess. In: Scheld WM, Whitley RJ, Marra CM, editors. Infections of the Central Nervous System. $4^{\text {th }}$ ed. Philadelphia, PA: Lippincott Williams \& Wilkins; 2014. p. 522-49.

9. Tunkel AR, Turtz AR. Posttraumatic infection of the central nervous system. In: RW Evans Neurology and Trauma. $2^{\text {nd }}$ ed. Oxford: Oxford University Press; 2006. p. 628-38.

10. Verma R, Singh P, Kumar A, Paliwal VK. Cranial aspergilloma masquerading as meningioma. BMJ Case Rep. 2013;2013. https://doi.org/10.1136/bcr-2012-008118 PMid:23307467

11. Alahmari AF. Medical treatment of brain aspergilloma followed by MRI: A case report. Radiol Case Rep. 2018;14(1):103-11. https://doi.org/10.1016/j.radcr.2018.09.021

PMid:30386448

12. Saini J, Gupta RK, Jain KK. Intracranial infections: Key neuroimaging findings. Semin Roentgenol. 2014;49(1):86-98. PMid:24342678

13. Sharma BS, Khosla VK, Kak VK, Banerjee AK, Vasishtha RK Prasad KS, et al. Intracranial fungal granuloma. Surg Neurol. 1997;47(5):489-97. https://doi.org/10.1016/ s0090-3019(96)00209-1 PMid:9131036

14. Murthy JM, Sundaram C, Prasad VS, Purohit AK, Rammurti S, Laxmi V. Aspergillosis of central nervous system: A study of 21 patients seen in a university hospital in South India. J Assoc Physicians India. 2000;48(7):677-81. https://doi. org/10.1046/j.1439-0507.2001.00643.x

PMid:11273500 